\title{
تصميم طباعة المنسوجات بين اللاغائية والتقنية
}

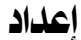

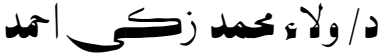 \\ مدرس بقسم طباعة المنسوجات والصباغة والتجهيز \\ كلية الفنون التطبيقية - جامعة دمياط
}

مجلة بحوث التربية النوعية ـ جامعة المنصورة

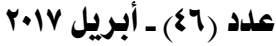


إعداد

* دولاء محمد زكراحمد

بين الوعى وغيابه ، وبوحِى من اعمال الابنية الباطنيه والعقل المبدع ، تتجلى الابداعات

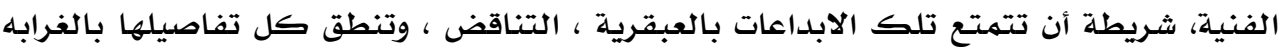

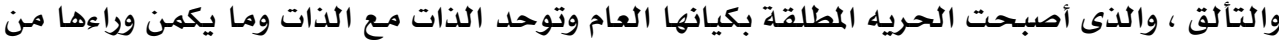
قيهم فنية يمثل محور الحسم فى طبيعتها الاستطيقية ومقوماتها الحضارية المنفردة .

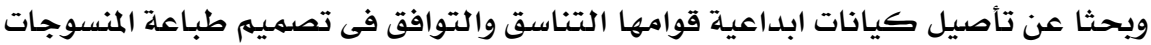

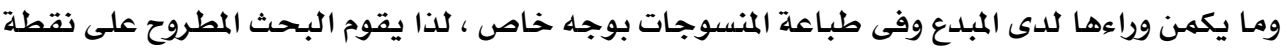

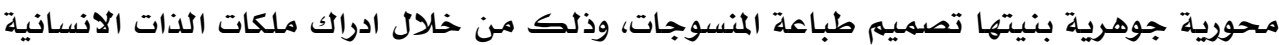
الباطنية وتحصيل اللذة الخالصة ورفض كل ما هو منهجى أو افتراضى بها يحقق اللاغائية فى

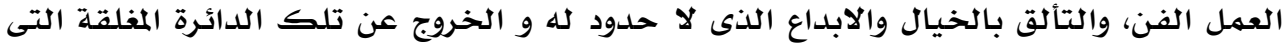

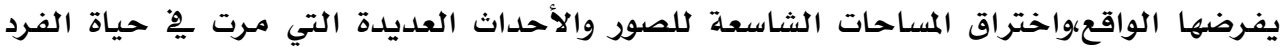

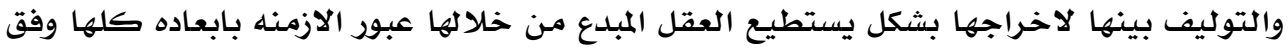

رؤية ابداعية فلسفية.

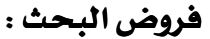
يفترض الباحث : ان لمفهوم اللاغائية والتقنية اثر ايجابى فى تفوق جماليات الشكل فى

تصميه طباعة المنسوجات . تصنئ

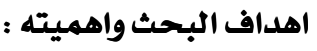

تكمن اهداف البحث وكذا اهميته في التهالى :

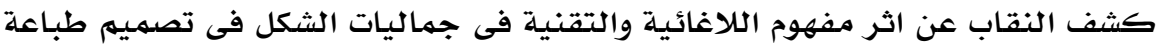
المنسوجات. حدود البحث

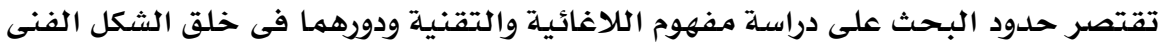
فى تصميهم طباعة المنسوجات من خلال دراسة فلسفية وتجريبية. منهجية البحث تقوم منهجية البحث على المنهج الوصفى التحليلى والمنهج التجريبى وذلك من خلال

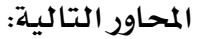

"مدرس بقسهم طباعة المنسوجات والصباغة والتجهيز - كلية الفنون التطبيقية - جامعة دمياط 


$$
\begin{aligned}
& \text { 1- - مفهوم الكلاغائية والتقنية فى تصميهم طباعة المنسوجات . } \\
& \text { r - - - أثر تصميهم طباعة المنسوجات بين النلاغائية والتقنية } \\
& \text { r- ب- النتائج والتوصيات }
\end{aligned}
$$

مقدهة

بين الوعى وغيابه ، وبوجى من اعمال الابنية الباطنيه والعقل المبدع ، تتجلى الابداعات

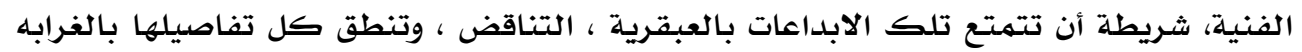

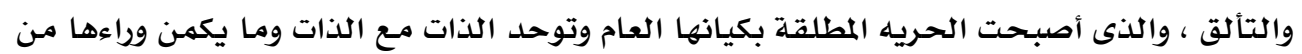
قيهم فنية يمثل محور الحسم فى طبيعتها الاستطيقية ومقوماتها الحضارية المنفردة .

وبحثا عن تأصيل كيانات ابداعية قوامها التناسق والتوافق فى تصميم طباعة المنسوجات

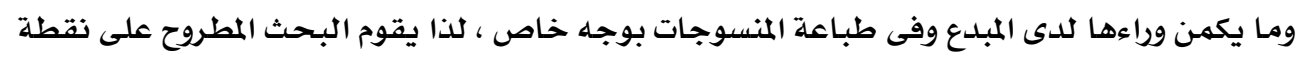

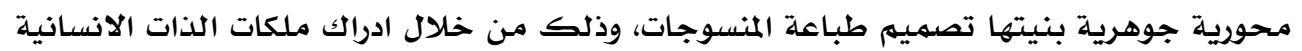

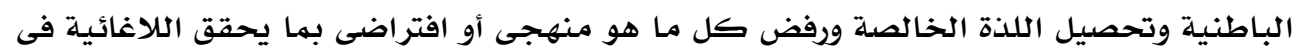

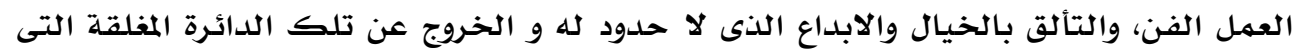

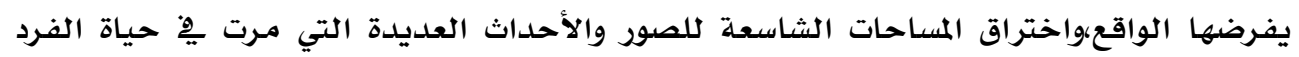

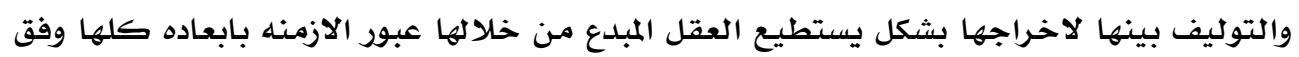

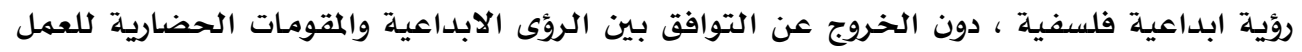

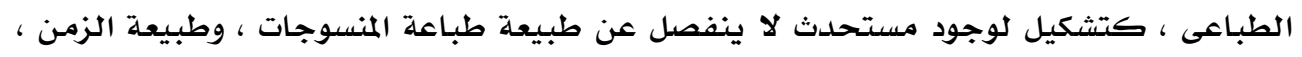

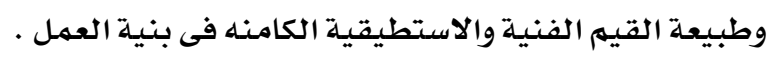

خلفية المشكلة :

من الطرح السابق يمكن لنا تحديد عدة محاور رئيسية تمثل فى مضمونها مشكلة البحث البح البه

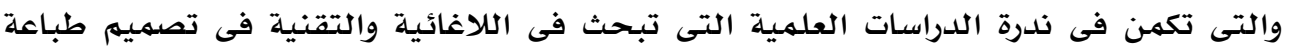

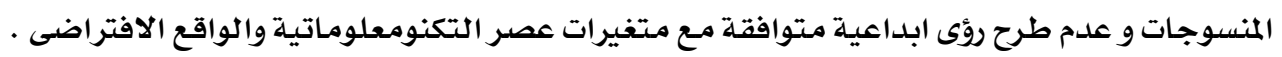

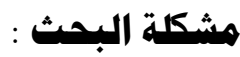

يمكن تحديد مشكلة البحث في التساؤل الاتية :

ما أثر مفهوم اللاغائية والتقنية فى اثراء جماليات الشكل فى تصميهم طباعة المنسوجات ؟

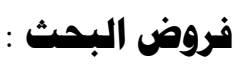
يفترض الباحث : ان لمفهوم اللاغائية والتقنية اثر ايجابى فى تفوق جماليات الشكل فى .

تصميه طباعة المنسوجات . 
تكمن اهداف البحث وكذا اهميته فى التالى :

كشف النقاب عن اثر مفهوم اللاغائية والتقنية فى جماليات الشكل فى تصميم طباعة المنسوجات.

\section{هدود البمث}

تقتصر حدود البحث على دراسة مفهوم اللاغائية والتقنية ودورهما فى خلق الشكل الفنى فئى

فى تصميه طباعة المنسوجات من خلال دراسة فلسفية وتجريبية.

تقوم منهجية البحث على المنهج الوصفى التحليلى والمنهج التجريبى وذلك من خلال المحاور التالية:

$$
\begin{aligned}
& \text { 1- مفهوم اللاغائية والتقنية فى تصميم طباعة المنسوجات . } \\
& \text { r- أثر تصميم طباعة المنسوجات بين اللاغائية والتقنية } \\
& \text { r- بـ النتائج والتوصيات. }
\end{aligned}
$$

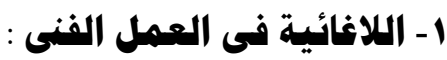

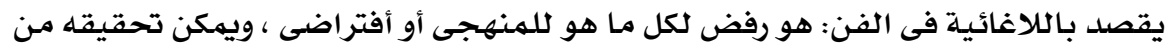

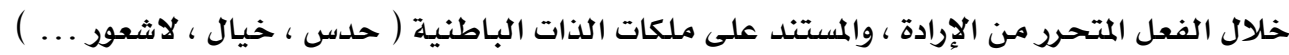

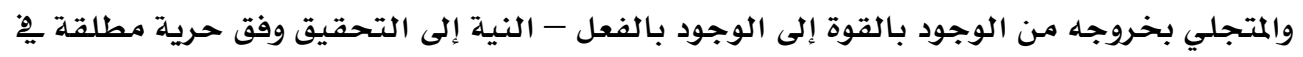

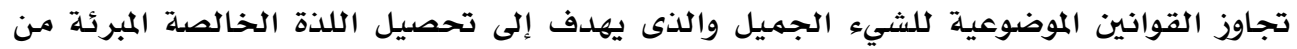

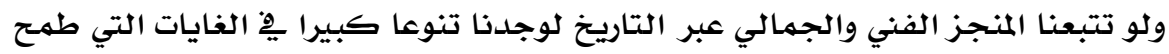

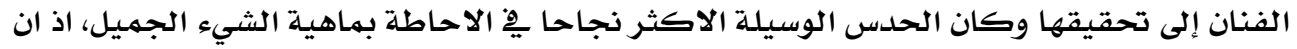

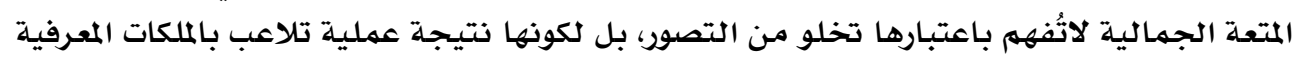

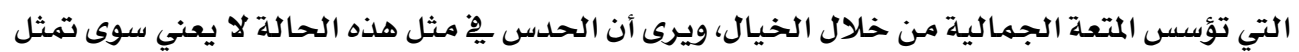

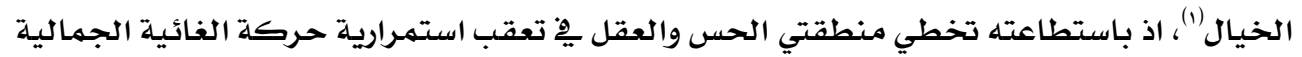

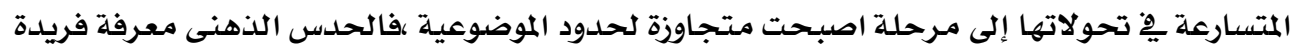

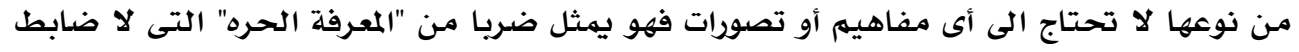


لها.") ومن هنا تنطلق اللاغائية فى الاتجاه المعاكس للغائية ، لتأخذ من الذات وملكاتها سبيلا

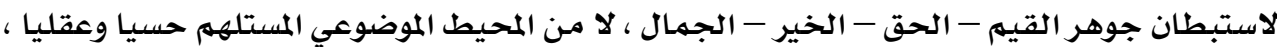

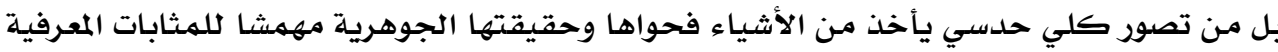

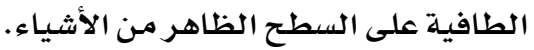

ومن هنا يأتى مفهوم اللاغائية فى العمل الفنى : فهو بمثابة البحث عن جمالية جديدة

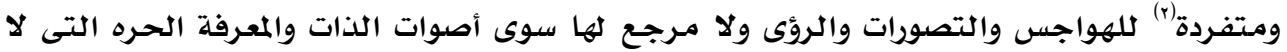
تقودنا اللى ادله وولا تحتاج الى تصورة لـوات.

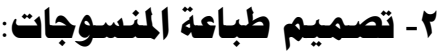

تبدأ عملية التصميهم من خلال الاحساس بحاجة ، سواء كانت هذه الحاجة معنويه أو مادية

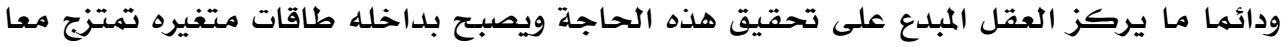

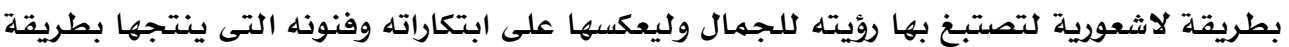

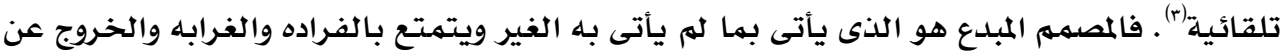

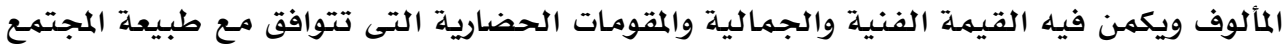

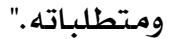

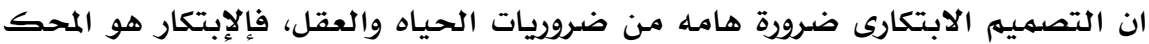

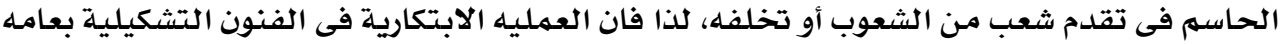

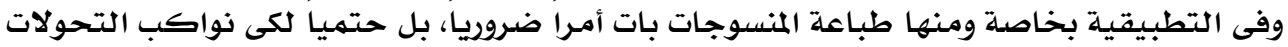
التى سادت العالم تكنولوجياً ورقمياً.

r- (التقنيه:

التقانة أو التقنية (\&) عرف التقنية بطريقتين: بأنها "السعي وراء الحيـاة بطرق مختلفـة عن

الحياة"، وبأنها "مادة لا عضوية منظمـة.

وتعني العلم التطبيقي الذي يهتم بدراسة الصناعات والفنـون والحـرف وكل مـا يتعلق بها مـن مـواد ووسـائل مستعمل ،فهي الطريقة التي تستعمل بهـا الخامـة الموظفـة ِِّْ إبـراز مـؤثرات العهـل

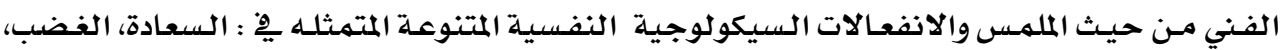

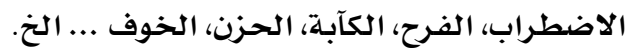

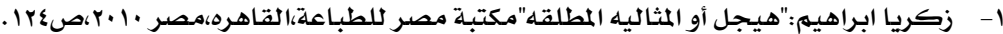

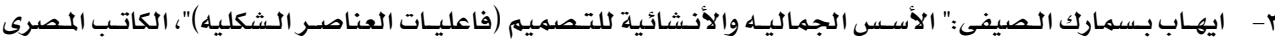

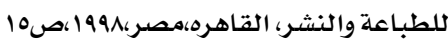

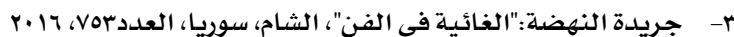
4- Stiegler, Bernard"Technics and Time, 1: The Fault of Epimetheus, Stanford University Press.1998 17,82، ISBN 0-8047-3041-3, P 
وترجمـة هـذه الانفعـالات لا تتتم إلا بـالتطرق للهـادة والشكل التي تتجسسد مـن خلالهـا ردود

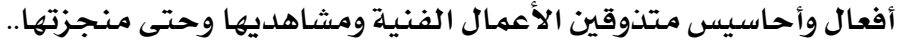

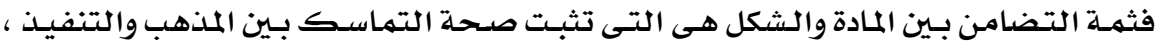

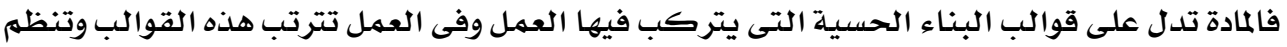

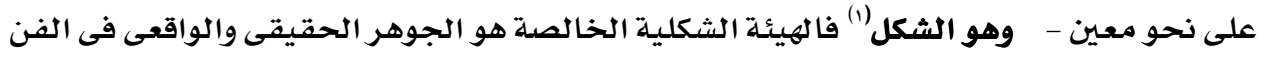

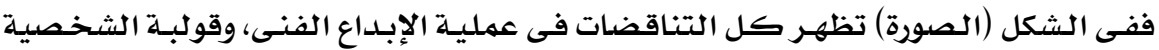

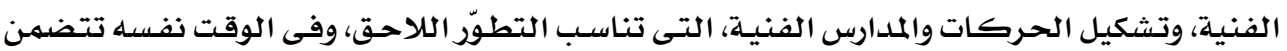

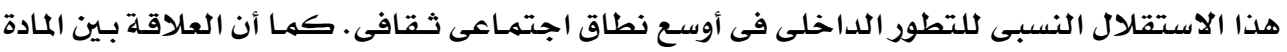

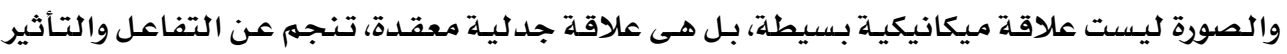

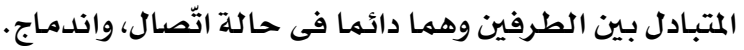

وفيما يلى عرض نهاذج لبعض تصميمات تم تنفيذها من قبل الباحث ، توضح تأثير التقنية

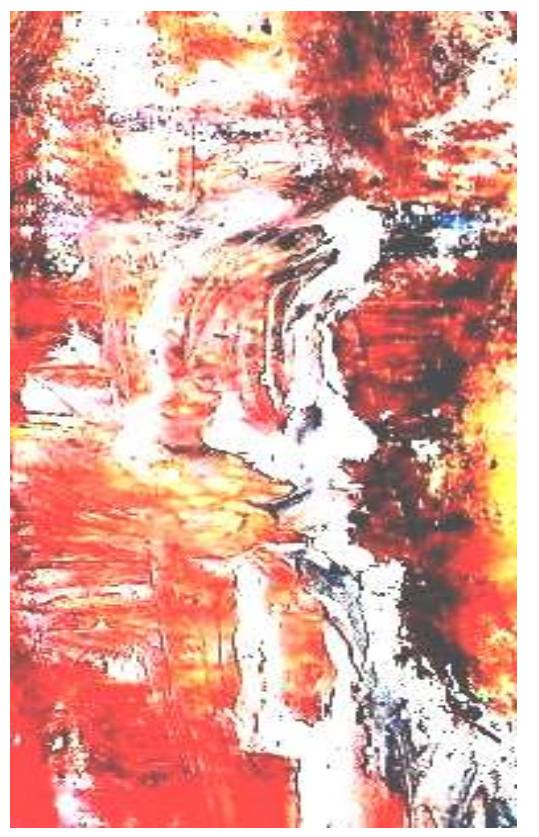

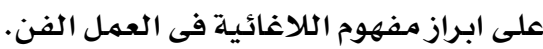

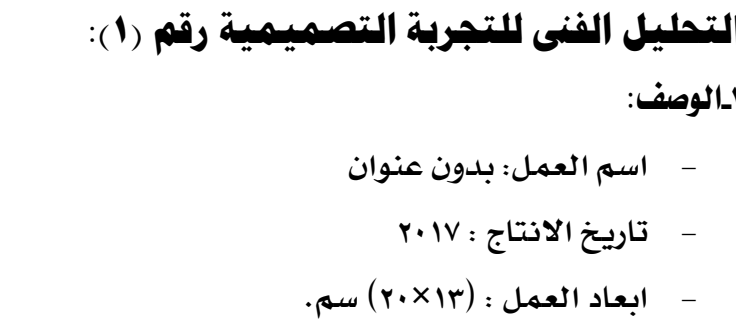

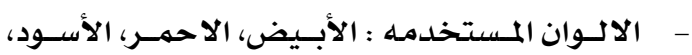

والاصفر والبرتقالى.

- الخامات والادوات: الوان زيتية على ورق.

- الغرض الوظيفى : " لوحات فنية"

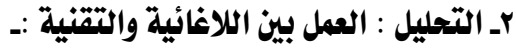

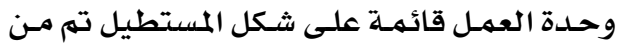

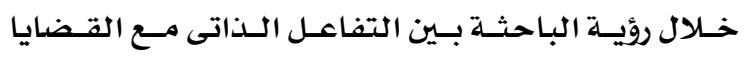

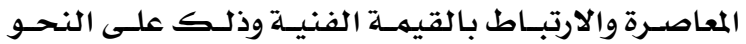

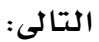

1- جيروم ستولينتز:" النقد الفنى دراسة جمالية وفلسفية "ترجمة فؤاد زكريا، دار الوفاء لدنيا الطباعة والنشر ،

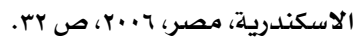




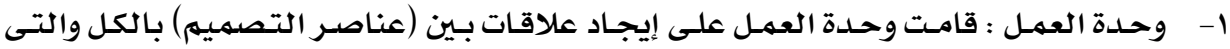

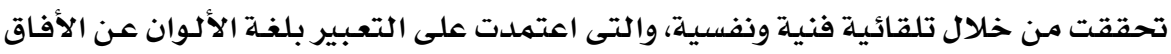

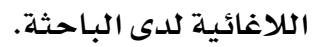

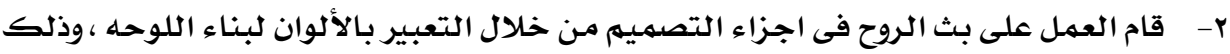

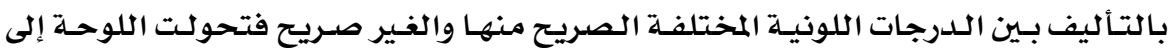

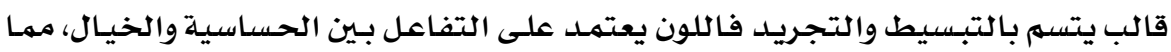

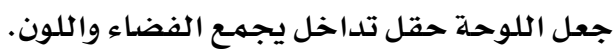

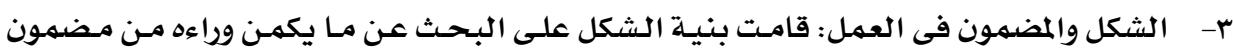

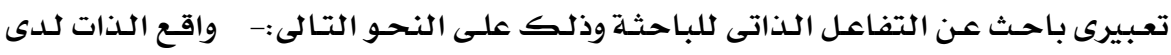

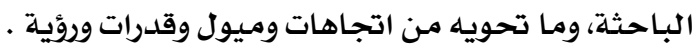

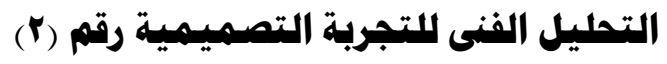

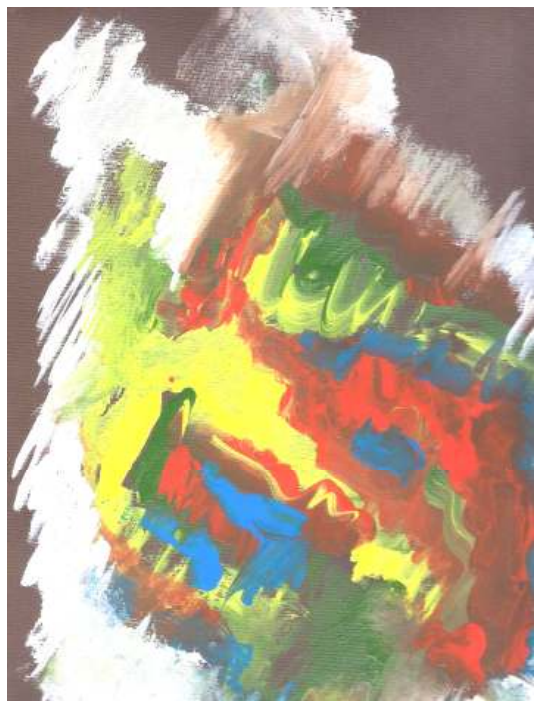

$$
\begin{aligned}
& \text { - اسهم العمل: بلدون عنوان } \\
& \text { r.IV : تاريخ الانتاج - }
\end{aligned}
$$

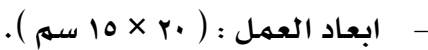

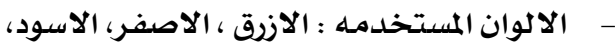

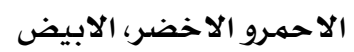

- الخامات والادوات: الوان زيتية على الورق - الغرض الوظيفى : "لوحات فنية"

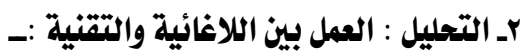

وحسـدة العهـل قائمسـة علـى شـكل المستطيل

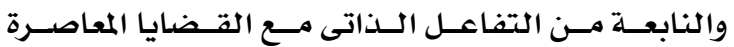

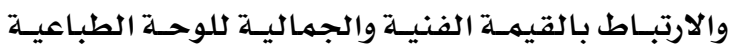
وذلك على النحو التالى:

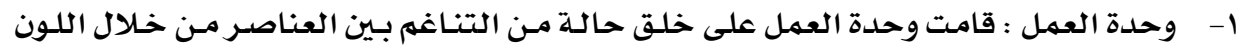

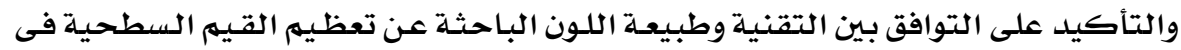

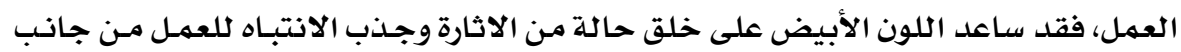

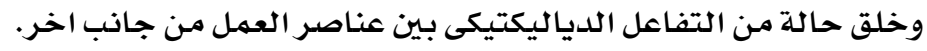

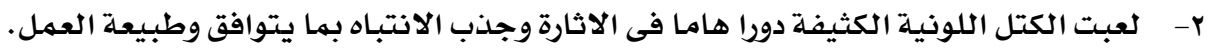



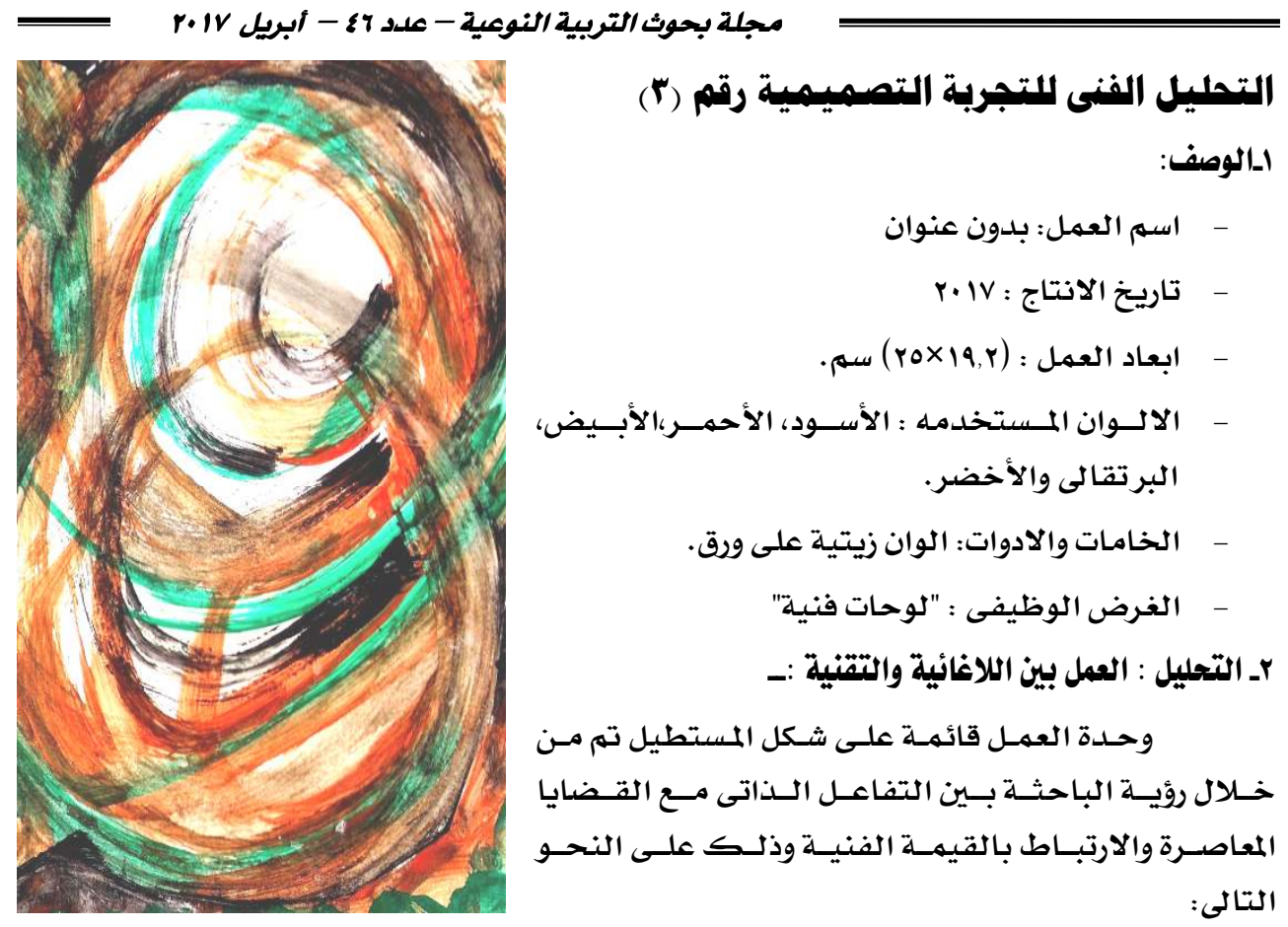

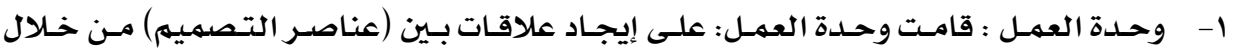

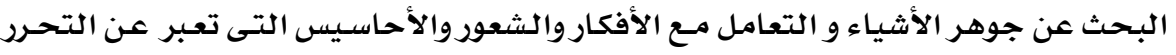

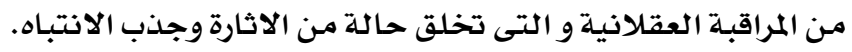

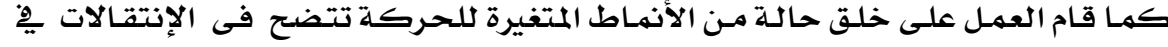

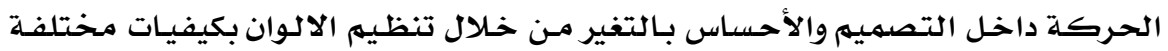

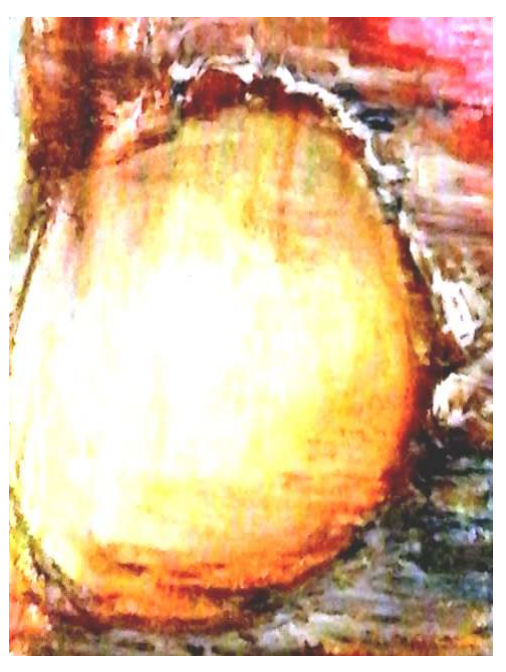
لأثاره العمليات الفسيولوجية البصرية.

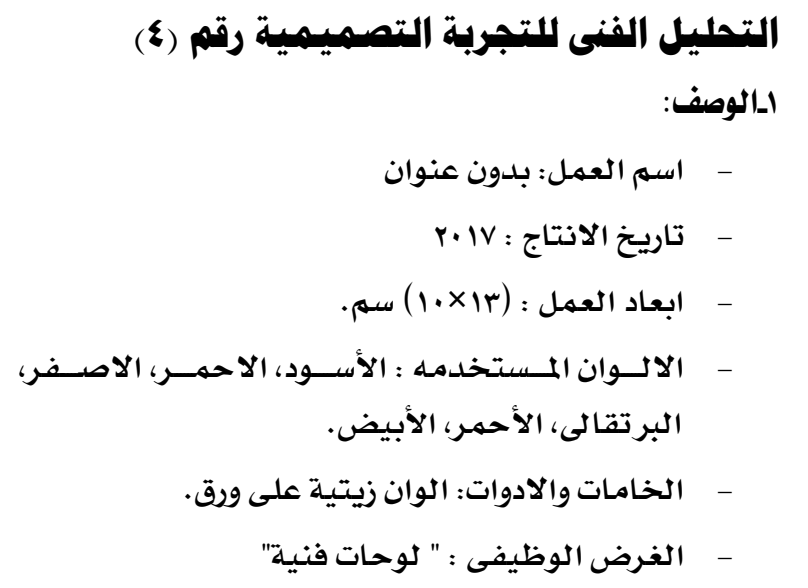




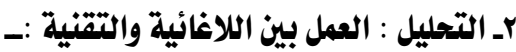

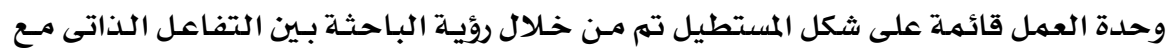

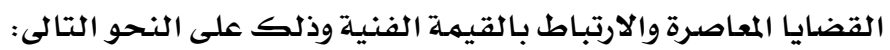

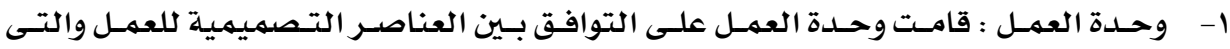

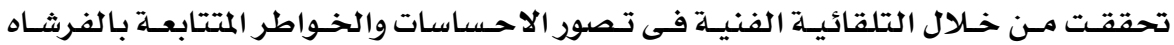
والنابعة من أغوار الباحثة دون عائق.

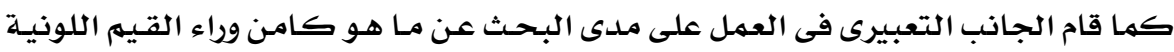

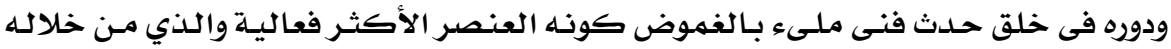

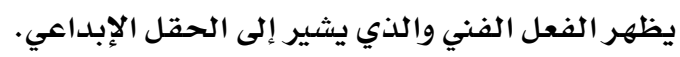

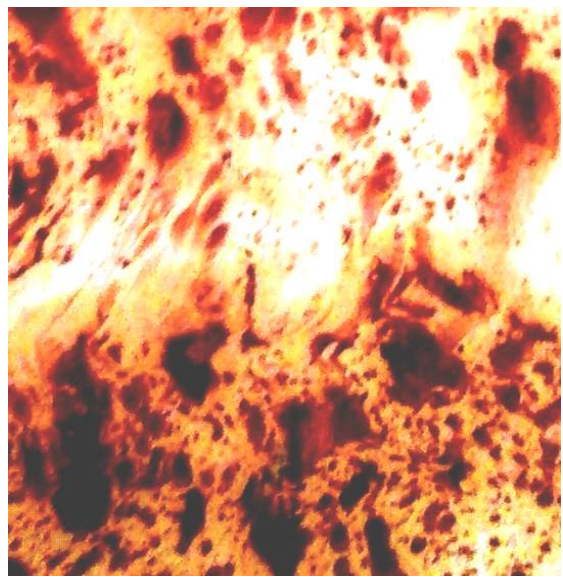

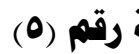
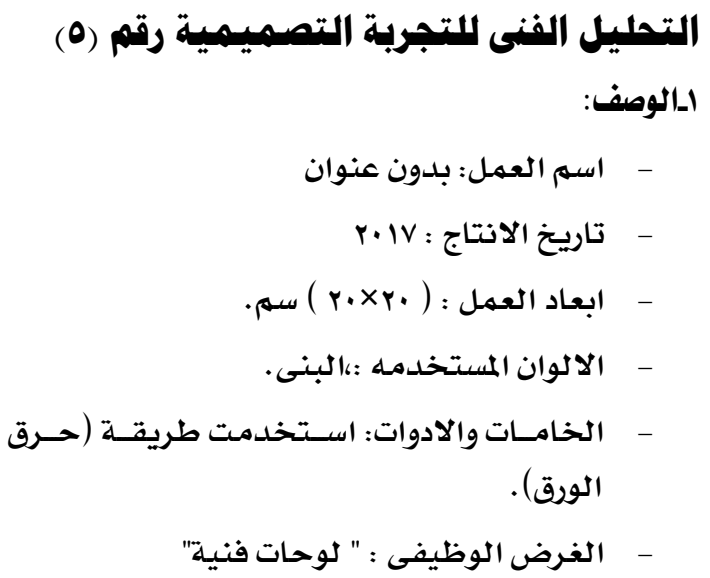

rـ التحليل : العمل بين اللاغائية والتقنية : لونية

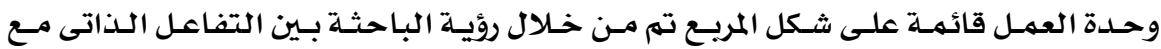

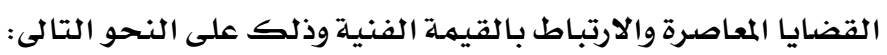

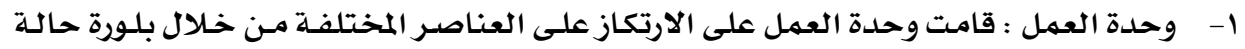

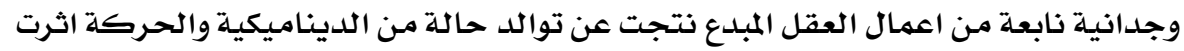

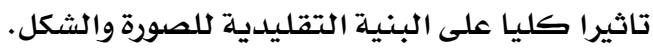

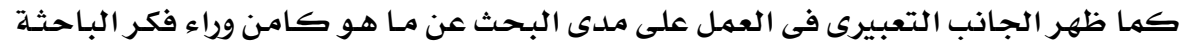

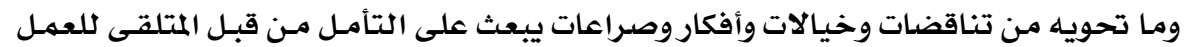

وتسلط الضوء عن الواقع المشوه. 

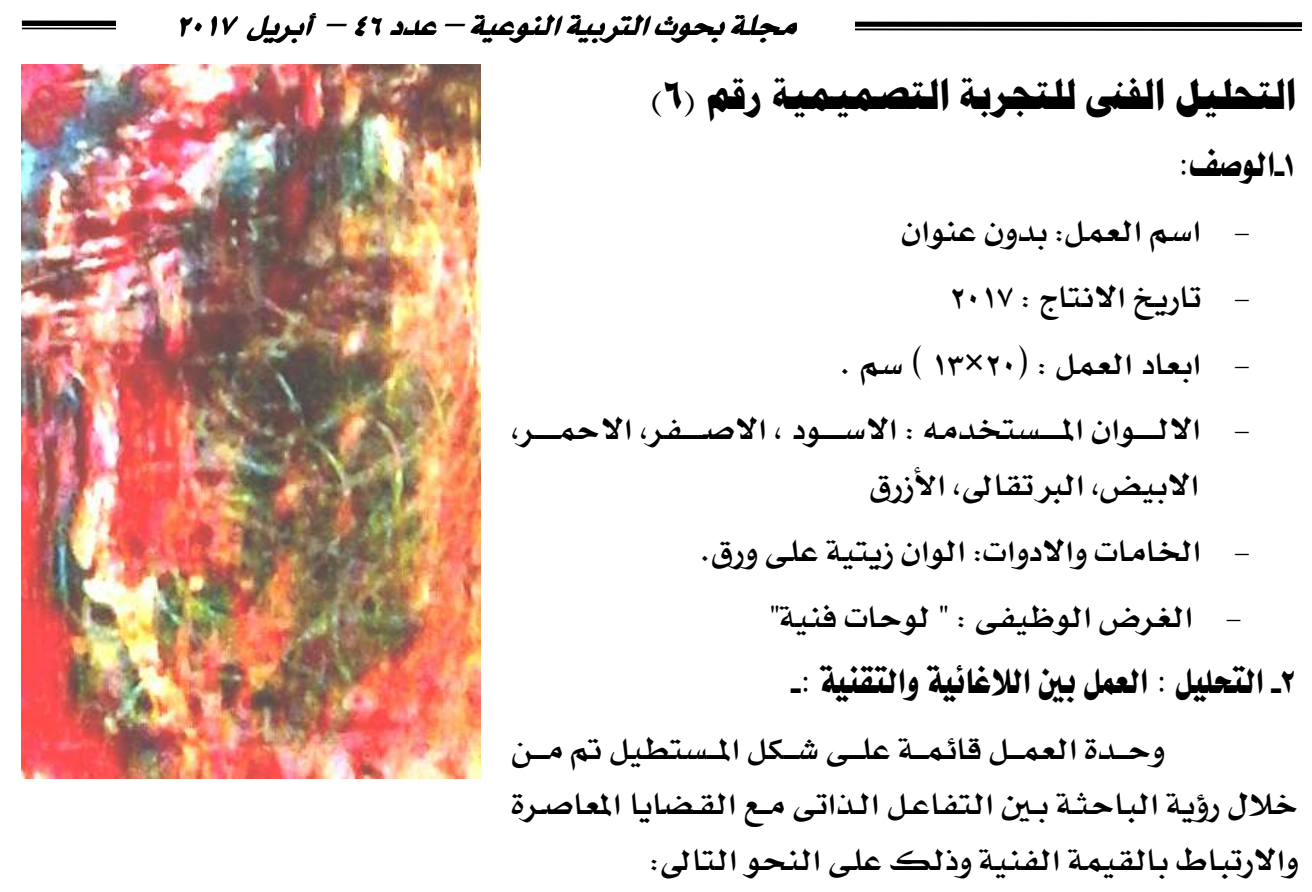

ا- وحدة العمل : قامت وحدة العمل على خلق حالة من التوهج الحسى بشعور أو خاطرة قادتها

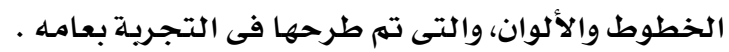

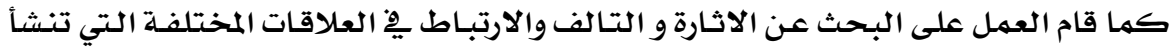

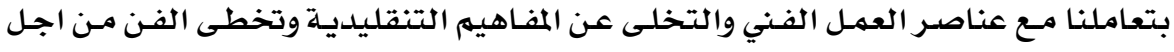

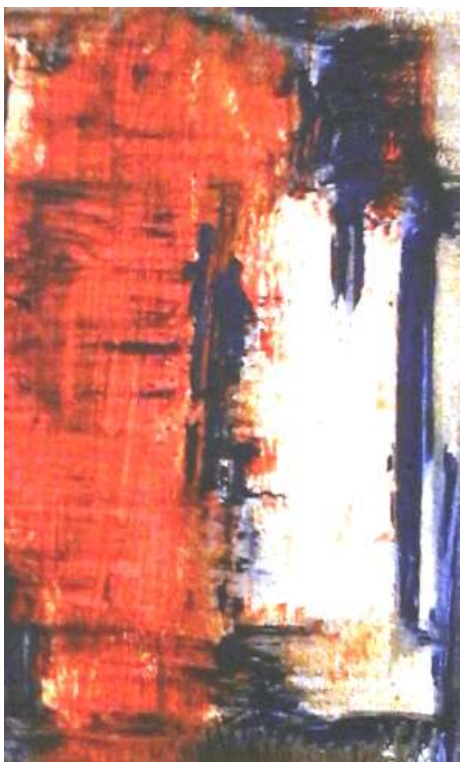
رؤيسة جديدة للواقع.

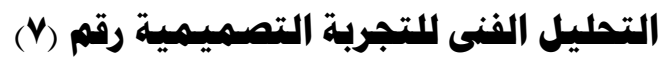
الوصف:

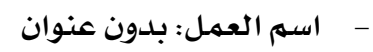
r.IV : تاريخ الانتاج -

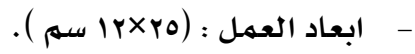

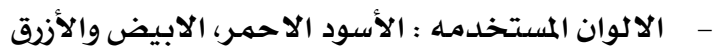
- الخامـات والادوات: الوان زيتية على ورق. - الغرض الوظيفى : " لوحات فنية" rـ التحليل : العمل بين اللاغائية والتقنية

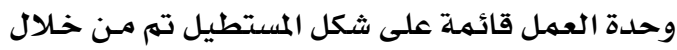

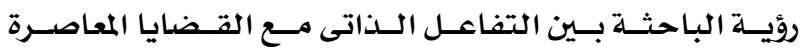




$$
\text { والارتباط بالقيمـة الفنية وذلك على النحو التالى: }
$$

ا- وحدة العمل قامت وحدة العمل الفني: على إيجاد علاقات بـين (عناصـر التصميم) مـن خـالال

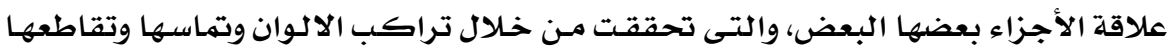

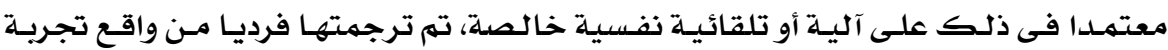
الباحثة .

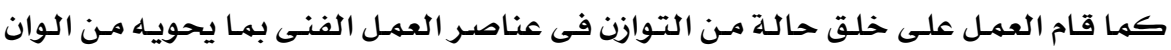

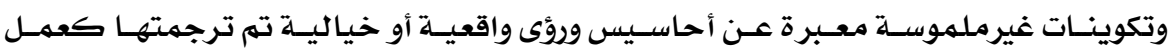

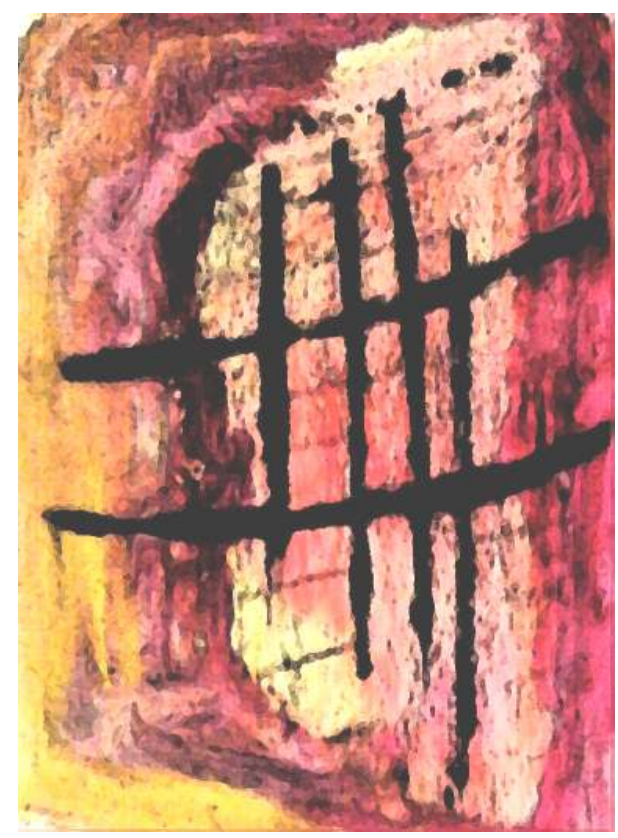
إبداعي ذات غاية كامنة منفردة.

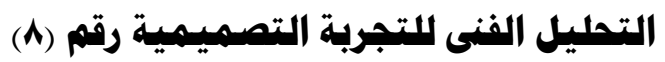
إ-الوصف:

$$
\text { - }
$$

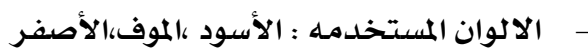

$$
\text { - الخامـات والادوات: الوان زيتية على ورق. }
$$

rـ التحليل: العمل بين اللاغائية والتقنية : لوحات فئية

وحدة العمل قائمة على شكل المستطيل

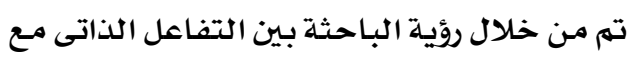

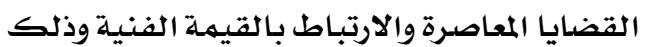

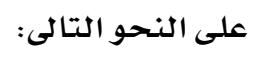

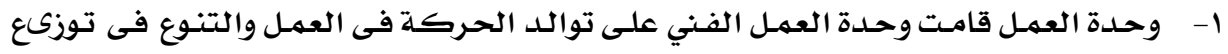

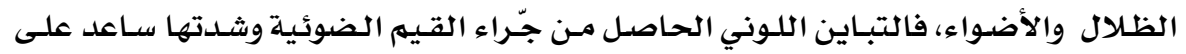

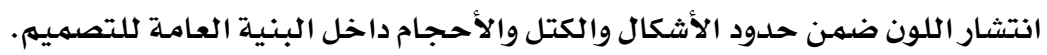

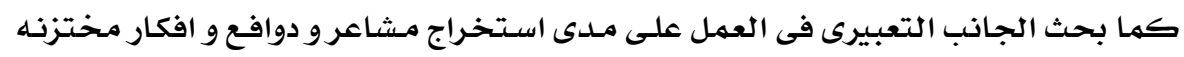

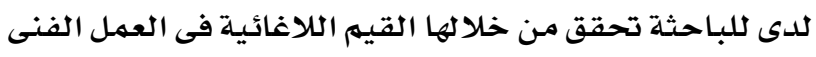
الخلاصة تعد الكلاغائية ضريا من "المعرفة الحره" التى لا ضابط لها والتى تنطلق من بين ثناياها

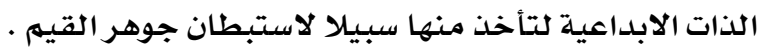


والفنان المبلدع يجسد عمله الفنى فى مادة معينة او واسطة معينة تقوم ببث الروح من خلال

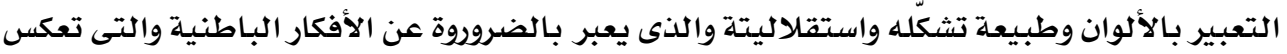

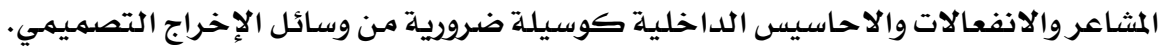

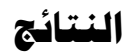

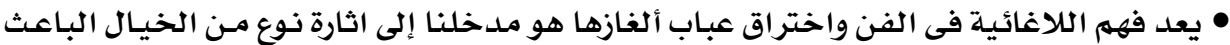

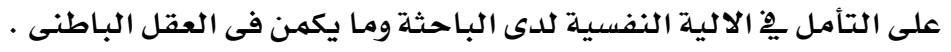

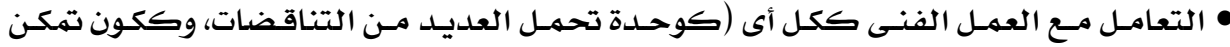
داخله الصراعات العديدة. ...الخ ).

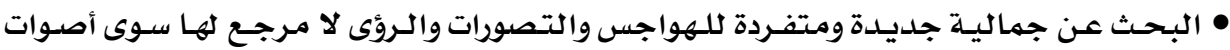

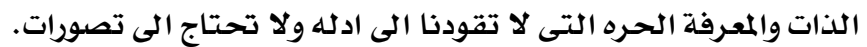

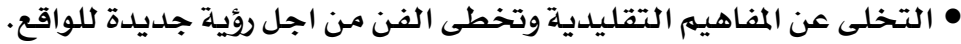

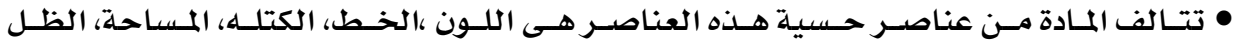
والنور..الخ. التوصيات

• العمل على تنـيـة الاحساس التاملى للوجدان وتحريك المشاعر نحو التعرف على كل مـا هـ كامن وراء اغوار المبدع.

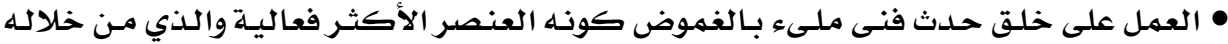

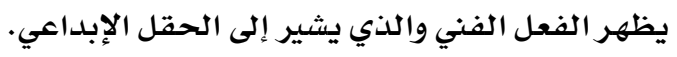

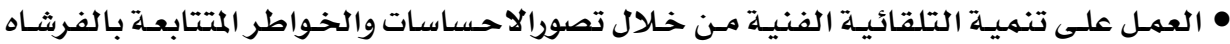
والتى تنبـع من العقل الباطنى الابداعي للباحثة دون عائق.

1- ايهاب بسمارك الصيفى:" الأسس الجماليه والأنثائية للتصميم (فاعليات العناصر الشكليه)"،الكاتب المصرى للطباعة والنشر، القاهره،مصر،1991. r- جان برتليمى:" بحث فى علم الجمال ترجمة انور عبد العزيز- نظمى لوقا ، دار نهضة مصر، القاهره ،

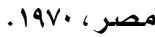
r- جيروم ستولينتز:" النقد الفنى دراسة جمالية وفلسفية "ترجمة فؤاد زكريا، دار الوفاء لدنيا الطباعة

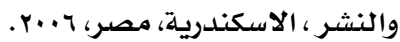

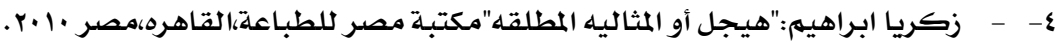
0- زكريا ابراهيهم : "فلسفة الفن فى الفكر المعاصر"، مكتبـة مصر ، القاهرة ، مصر، 1911 ـ . ؟- ناصر الحجيلان:" الحدس والتصوّر الجمالي ضمن رؤيلة العالم" مقاله بجريدة الرياض،المملكة العربية

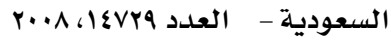


ثانيا: المراجع الاجنبية

7- Stiegler, Bernard"Technics and Time, 1: The Fault of Epimetheus, Stanford University Press.1998 17,82، ISBN 0-8047-3041-3 , P

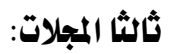

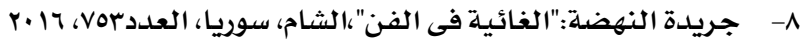




\section{Abstract}

Between the consciousness and absence, and inspired by the works of the inner buildings and the creative mind, all of these reflected artistic creations, provided that these innovations enjoy genius, contradiction, and utter all the details of gravity, which has become absolute freedom in its general entity and self-unity with the self and the underlying technical values is the focus of the individual merits of civilization.

In search of creative entities, strong consistency and compatibility in textile printing design and what lies behind the creative and in textile printing, in particular, so the focal point of a fundamental structure of the design of textile printing, shows through realizing human self inner queens and the collection of pure pleasure and rejection of all is a systematic or hypothetical to achieve art.

The objectives of the research as well as its importance in the following: Research hypotheses

The researcher assumes that the concept of negativity and technique has a positive effect on the superiority of shape aesthetics in the design of textile printing.

\section{Research objectives and importance}

The research objectives are as follows

Revealing the effect of the concept of the technique in the design aesthetics in the design of textile printing

\section{Search limits}

The limits of the research are limited to the study of the concept of the technique and its role in creating the artistic form in the design of textile printing through a philosophical and empirical study

\section{Research Methodology}

The research methodology is based on the analytical descriptive approach and the empirical approach through the following axes 
1-the concept of non-technical and technical in the design of textile printing

2- The effect of the design of textile printing between non-technical and technical

.3- Conclusions and recommendations 